transfusions she would be more likely to be a carrier of the virus of serum hepatitis, and this additional risk would have to be considered before using her blood for transfusion to other patients.

\section{Anorexia Nervosa}

Q. - A girl of 15 with severe anorexia nervosa is being given electro-convulsive therapy, which results in only shortlived improvement. Has physical treatment now replaced the textbook insistence on isolation, vigorous persuasion, and skilled nursing in this condition?

A. - The best treatment of anorexia nervosa still consists in removing the patient from all contact with home and friends and treating her with rest, encouragement, and controlled feeding in hospital. The results are usually excellent.

\section{Fear of Pregnancy}

Q.-A patient of mine, after three years of marriage, has been unable to achieve intercourse owing to an intense fear of pregnancy. According to a distinguished psychologist she required a long course of re-educative treatment by $a$ psychologist to correct these faulty ideas. This is economically impossible. I endeavoured to carry out this procedure and arranged for her to help in the wards at a local maternity hospital. This improved her outlook, and she was impressed by the happiness of young mothers and developed a desire for a child of her own. After a long period she witnessed a delivery, and at the conscious level was amazed at the ease with which the child was born and the satisfaction the mother experienced. A few days later, however, she became tense, distraught, and agitated, and her hopeful attitude towards an ultimate cure completely disappeared. What treatment can be recommended? Have the exponents of hypnotism any short cut to success? Might she have solved her difficulties if I had postponed her entrance to the labour ward for a longer period?

A.-If specialist treatment by a psychiatrist is not available, sympathetic listening to the patient's complaint as she repeatedly tells it, meanwhile reassuring her that she may be able to work her way gradually to an understanding of how her trouble began and how it can be overcome, may help. If, when seen, she ceases to complain and does not know what to talk about, she can be asked to tell all she remembers or has heard about her own bowel and bladder training (especially whether she had periods of constipation treated by enemas or laxatives), intercourse, and childbirth. This may lead her to discover the source of her fear and the way in which it can be overcome. Her conscious worry about pregnancy certainly hides other fears which will have to be discussed before they can be alleviated.

With regard to hypnosis, it can of course be said that for centuries such treatment has helped some patients. One can also say that the help obtained by hypnosis depends more on the personality of the hypnotist and his relation to the patient than on the technique of hypnosis, but the type of patient who can be helped by hypnosis is not easy to select.

Most likely the hopefulness and hopelessness of such a patient will vary very much from time to time. Following any period when her hope increases (unless this hope leads to a radical change in her condition with success in intercourse), it will probably be followed by a period of depression and hopelessness. Even when she has improved sufficiently to have satisfactory intercourse, pregnancy would probably be associated with another period of depression and anxiety, from which in a shorter or longer time she might well recover. It is likely that both the satisfaction and hope she obtained while working in a labour ward and the later depression and hopelessness would have occurred in any case. In the long run, her new knowledge of how satisfactorily women can go through pregnancy and labour is unlikely to be other than a help to her.

\section{Lucifers}

Q. -What is the chemical composition of the fumes from the burning head of (a) a "safety" and (b) a " non-safety" match?

A.- The fumes are substantially the same in both "safety" and "non-safety" matches, though the proportion of the constituents-mostly sulphur dioxide, carbon dioxide, nitrogen, oxygen, and water-differs.

\section{Case for Diagnosis}

Q.-The following case was seen recently: A soldier of 19 complained of pain over the right brow and face which appeared very severe; when left to himself he would sit holding his face. The pain was described as a dull ache. Examination showed hyperaesthesia limited to the ophthalmic and maxillary divisions of the trigeminal nerve. The corneal reflexes were brisk and equal. On the following day there supervened anaesthesia both to touch and pinprick over the areas previously hyperaesthetic. Corneal reflexes were preserved and normal. Palatal sensitivity was normal. There was no masseter or pterygoid weakness. Forty-eight hours later sensation had completely returned. What was the diagnosis?

A.-Almost certainly the soldier's pain was genuine, probably due to a carious right upper molar or antral infection, and the trigeminal hyperaesthesia was the first reflex reaction. The succeeding anaesthesia was clearly functional, proved not only by its rapid complete disappearance but by the anaesthesia to pin and touch being limited to the superficial cutaneous area, and not involving the mucous membranes of palate, conjunctiva, and cornea. It is most unlikely for loss to pin and touch (thermal and pressure sensations in this case are not recorded) to be limited to two anatomical trigeminal divisions. In the pons and medullary nuclei tactile and pain trigeminal conduction are very dissimilar, the former being transmitted through the principal sensory nucleus in the upper pons, while the pain fibres run caudally in the descending spinal root, ending in its special medullary nucleus. These two sets of fibres then decussate quite separately and run up the opposite side of the pons rostrally in two separate bundles to the crus and thalamus.

\section{NOTES AND COMMENTS}

Stains and Medicinal Dyes.-Dr. T. A. Hunr (East Midlands Division, National Coal Board) writes: With reference to your queștion on stains and medicinal dyes ("Any Questions?" June 21, p. 1366), we find in practice in the Mines Surgeries in No. 5 Area of the East Midlands Division that gentian violet and brilliant green stains are removed from skin and materials by sal volatile or " instrument dettol." The instrument dettol appears to be more satisfactory and does not cause a soreness of the skin, as frequently occurs with sal volatile.

Correction.- In the article by Mr. A. H. Hunt on "The Surgical Treatment of Banti's Syndrome" (July 5, p. 4) an error occurred on p. 8, column 2, first paragraph under " Group IV: The Terminal Stages of Cirrhosis (Table IV)." The first sentence should read: "Table IV completes the background against which the results of this report must be judged."

\footnotetext{
All communications with regard to editorial business should be addressed to THE EDITOR, BRITISH MEDICAL Journal, B.M.A. HOUSE, TAVISTOCK SQUARE, LONDON, W.C.1. TELEPHONE: EUSTON 4499. TELEGRAMS Aitiology, Westcent, London. ORIGINAL ARTICLES AND LETTERS Medical Journal alone unless the contrary be stated.

Authors desiring REPRINTS should communicate with the Publishing Authors desiring REPRINTS should communicate with the Publishin Manager, B.M.A. House, Tavistock Square, W.C.1, on receipt of proofs. proofs are not sent abroad.

ADe Advertisement Manager B.M.A. House, Tavistock Square, London, W.C.1 (hours 9 a.m. to EUSTON 4499. TELEGRAMS: Britmedads,

MEMBERS' SUBSCRIPTIONS should be sent to the SECRETARY of the Association. TelePHONE: EUSTON 4499. Telegrams: Medisecra,

B.M.A. ScotTISH OFFICE：7, Drumsheugh Gardens, Edinburgh.
} 